\title{
Extracellular Biosynthesis of Monodispersed Gold Nanoparticles, their Characterization, Cytotoxicity Assay, Biodistribution and Conjugation with the Anticancer Drug Doxorubicin
}

\author{
Asad Syed", Remya Raja², Gopal. C.Kundu², Sanjay Gambhir ${ }^{3}$ and Absar Ahmad ${ }^{1 *}$ \\ ${ }^{1}$ Division of Biochemical Sciences, National Chemical Laboratory, Pune-411008 (M.S), India \\ ${ }^{2}$ National Centre for Cell Science, Pune-411007 (M.S), India \\ ${ }^{3}$ Department of Nuclear Medicine, SGPGIMS, Lucknow- 226014 (U.P), India
}

\begin{abstract}
Nanomaterials can be synthesized by chemical, physical and the more recent biological routes. Biological routes have many advantages as these are eco-friendly, cheap, non-toxic, do not flocculate, and are well dispersed in water. Gold nanoparticles have shown significant promise as drug carriers, and have been used in the past for targeted drug delivery applications. In this report, we for the first time, have produced monodispersed gold nanoparticles through a green-synthesis approach employing thermophilic fungus Humicola spp. Out of several microorganisms screened, Humicola spp. was found to reduce the precursor solution $\left(\mathrm{HAuCl}_{4}\right)$ at just $50^{\circ} \mathrm{C}$, and lead to the formation of gold nanoparticles of 18-24 nm size with good dispersity, uniform spherical morphology and high stability. These nanoparticles were completely characterized by different standard techniques. Their biocompatibility, cytotoxicity and radiolabeling studies were carried out. Lastly, these nanoparticles were also conjugated with the anticancer drug Doxorubicin, for targeted drug delivery to liver (hepatic) cancer.
\end{abstract}

Keywords: Gold nanoparticles; Biosynthesis; Monodispersed; Humicola spp.; Biodistribution

\section{Introduction}

A variety of chemotherapeutic agents such as taxol [1,2], 5-fluorouracil [3], dexamethasone [4], vinblastine, vincristine, etc. are being used to deal with a variety of cancers, which remains to be the most dreadful disease till date. However, the use of chemotherapy not only kills the cancer cells, but also targets the normal living cells. The therapeutic agents used, invade the affected sites and then carry on to freely move through the circulatory system, affecting various other areas of the body and causing major side effects [5]. Thus, the need of the hour is to focus research upon the targeted delivery of drugs, so that minimum amount of drug would be sufficient to cure the disease, thus preventing wastage of valuable drugs and sparing the normal cells in the process [5].

In recent years, the use of nanoparticles in targeted drug delivery systems has gained immense popularity, as these can improve the uptake of poorly soluble drugs by the diseased cells, thus reducing the amount of drug to be used, and are also very site-specific [6,7]. Free drug, without being conjugated to nanoparticles, manages to enter the tumor cell by diffusion, but is immediately effluxed by the P-glycoprotein receptors present in the tumor cell, and thus a very insignificant amount of drug actually enters the diseased cell. Keeping this under consideration, researchers synthesized a conjugate of nanoparticle, drug and a target molecule, wherein the nanoparticles act as carriers and assist in receptor mediated endocytosis to achieve target specific drug delivery. Once the drug is conjugated with nanoparticles, the dimensions of the conjugate become favorable for easy uptake by the tumor cells via endocytosis $[8,9]$.

It is now well known that cancer cells overexpress various receptors like hFR (folate receptors), EGFR (Epidermal Growth Factor Receptor), EpCAM (Epithelial Cell Adhesion Molecule), Asialoglycoprotein [10-13], etc. These receptors are being used as potential drug targets in cancer therapy, where they are recognized by their specific target molecules associated with the nano-drug conjugate. For example, asialoglycoprotein receptors are present in abundance in liver and more importantly, are overexpressed in liver cancer. Pullulan is a compound which is known to have specific affinity for the asialoglycoprotein receptors. Thus, pullulan is being used in liver targeted drug delivery system by covalently coupling it with the drug Doxorubicin, which is most widely used for the treatment of liver (hepatic) cancer. The problems arising in free administration of this drug were related to multidrug resistance and acute renal- and cardiotoxicity, as the drug is fatal to normal tissues. Thus, doxorubicin coupled with nanoparticles and pullulan has been successful in treating hepatic cancer, with no side-effects, as only a minimum amount of dosage is required, which results in high intracellular concentrations of the drug in specific tumor cells only, thereby preventing the loss of this expensive and valuable drug [14]

The nanoparticles so far being used in targeted drug delivery systems are being synthesized by physical and chemical routes [15]. The chemical routes are toxic and require extremes of temperature, while the physical ones are expensive and laborious. Unlike these, biological routes for the synthesis of nanoparticles have recently been developed and yield nanoparticles at room temperature and physiological $\mathrm{pH}$, with properties such as high stability, water dispersal, fluorescence, etc., which are very difficult to achieve by chemical and physical routes [16-22]. Moreover, biologically synthesized nanoparticles are naturally

*Corresponding author: Dr. Absar Ahmad, Division of Biochemical Sciences, National Chemical Laboratory, Pune-411008 (M.S), India, Tel: 91-20-25902226 Fax: +91-20-25902648; E-mail: a.ahmad@ncl.res.in

Received October 12, 2012; Accepted November 28, 2012; Published November 30, 2012

Citation: Syed A, Raja R,Kundu GC, Gambhir S, Ahmad A, et al. (2013) Extracellula Biosynthesis of Monodispersed Gold Nanoparticles, their Characterization, Cytotoxicity Assay, Biodistribution and Conjugation with the Anticancer Drug Doxorubicin. J Nanomed Nanotechol 4: 156. doi:10.4172/2157-7439.1000156

Copyright: ( 2013 Syed A, et al. This is an open-access article distributed under the terms of the Creative Commons Attribution License, which permits unrestricted use, distribution, and reproduction in any medium, provided the original author and source are credited. 
Citation: Syed A, Raja R,Kundu GC, Gambhir S, Ahmad A, et al. (2013) Extracellular Biosynthesis of Monodispersed Gold Nanoparticles, their Characterization, Cytotoxicity Assay, Biodistribution and Conjugation with the Anticancer Drug Doxorubicin. J Nanomed Nanotechol 4: 156. doi:10.4172/2157-7439.1000156

protein capped, which prevents their flocculation, thus eliminating the need of any external capping agent, which are usually toxic as is seen in chemical routes. Thus, the biosynthesis of nanoparticles is in complete synchronization with the environment and should be further developed in order to obtain nanoparticles of variable sizes, shapes and chemical compositions, which will find major applications in targeted drug delivery systems [23,24]. Gold nanoparticles are bio-compatible and non-toxic [25], and have already been reported to have tremendous potential as carriers of drugs.

The aim of the present study was to synthesize monodispersed nanoparticles, to be used in targeted drug delivery for treatment of cancers, with properties such as bio-compatibility, high stability, nontoxicity etc., which would further aid in its conjugation to the drug and target molecule. Moreover, we made significant attempts in order to obtain the nanoparticles in the size range of $10-50 \mathrm{~nm}$, so that these inorganic particles may not block the glomerulus of the kidneys and may easily pass through the urine within a short period of time. This is the first report of its kind where nanoparticles have been synthesized by using a biological route employing Humicola spp., so that they may further be developed to find applications in targeted drug delivery systems.

\section{Materials and Methods}

\section{Materials}

Chloroauric acid $\left(\mathrm{HAuCl}_{4}\right)$ was obtained from Sigma Aldrich; malt extract, yeast extract, glucose and peptone were obtained from HiMedia and used as-received.

\section{Isolation of the fungus Humicola spp. (AAH-SCH-1)}

The fungus Humicola spp. was isolated from self heating compost samples that were collected from Pune district of Maharashtra, India. The hyphal tip and single spore isolation methods were employed for the isolation of fungus [26]. The fungus was identified by cultural, morphological and molecular methods.

\section{Fungal growth and maintenance}

The isolated fungus was maintained on MGYP [malt extract (0.3\%), glucose (1\%), yeast extract $(0.3 \%)$, and peptone $(0.5 \%)]$ agar slants. Stock cultures were maintained by sub-culturing at monthly intervals. After growing the fungus at $\mathrm{pH} 9$ and $50^{\circ} \mathrm{C}$ for 4 days, the slants were preserved at $15^{\circ} \mathrm{C}$. From an actively growing stock culture, subcultures were made on fresh slants, and after 4 days of incubation at $\mathrm{pH} 9$ and $50^{\circ} \mathrm{C}$, the same were used as the starting material for biosynthesis of gold nanoparticles.

\section{Extracellular biosynthesis of gold nanoparticles by Humicola spp.}

For the biosynthesis of gold nanoparticles, the fungus was grown in $250 \mathrm{~mL}$ Erlenmeyer flasks, containing $100 \mathrm{~mL}$ of MGYP medium. Sterile $10 \%$ sodium carbonate was used to adjust the $\mathrm{pH}$ of the medium to 9 . After the $\mathrm{pH}$ of the medium was adjusted, the culture was grown with continuous shaking on a rotary shaker $(200 \mathrm{rpm})$ at $50^{\circ} \mathrm{C}$ for $96 \mathrm{hr}$. After $96 \mathrm{hr}$ of fermentation, mycelia were separated from the culture broth by centrifugation $(5000 \mathrm{rpm})$ at $20^{\circ} \mathrm{C}$ for $20 \mathrm{~min}$, and then were washed thrice with sterile distilled water under sterile conditions. The harvested mycelial mass ( $20 \mathrm{~g}$ of wet mycelia) was then resuspended in $100 \mathrm{~mL}$ of aqueous solution of $1 \mathrm{mM} \mathrm{HAuCl}_{4}$ in $250 \mathrm{~mL}$ Erlenmeyer flasks, and the same was put onto a shaker at $50^{\circ} \mathrm{C}(200 \mathrm{rpm})$. The reaction was carried out for a period of $96 \mathrm{hr}$ and fungal biomass was separated by filter- paper to collect biomass and filtrate in sterile conditions. Periodically, aliquots of the reaction solution were removed and subjected to UV-vis spectroscopy, to check the formation of nanoparticles extracellularly.

\section{Characterization of biosynthesized gold nanoparticles}

The optical properties of gold nanoparticles were examined by using UV-vis spectroscopy. The measurements were performed on a Shimadzu dual-beam spectrophotometer (model UV-1601 PC), operated at a resolution of $1 \mathrm{~nm}$. The nanoparticles were also characterized by using Transmission Electron Microscopy (TEM) and X-ray Diffraction (XRD) measurements. The biosynthesized nanoparticles solution was drop casted on a carbon coated copper grid and analyzed using JEOL $1200 \mathrm{EX}$ instrument, operated at a voltage of $80 \mathrm{kV}$. The Selected Area Electron Diffraction (SAED) analysis was carried out on the same grid. HRTEM images were scanned on FEI Technai G2 system, operated at an accelerating voltage of $300 \mathrm{kV}$ at room temperature. The XRD pattern was obtained on a Philips PW 1830 instrument operating at 40 $\mathrm{kV}$, and at a current of $30 \mathrm{~mA}$ with $\mathrm{Cu} K_{\alpha}$ radiation $(\lambda=1.5404 \AA)$. X-ray photoelectron spectra were recorded on VG MicroTech ESCA 3000 instrument. FTIR spectra of gold nanoparticle solution was recorded on Perkin Elmer spectrum one B in diffuse reflectance (DRS) mode at a resolution of $2 \mathrm{~cm}^{-1}$. Energy Dispersive Analysis of X-rays (EDAX) was carried out on a Leica Stereoscan-440 SEM equipped with a Phoenix EDAX attachment. EDAX spectra were recorded in the spot-profile mode by focusing the electron beam onto a region on the surface coated with nanoparticles.

\section{Cell Viability Assay}

The effect of nanoparticles on the proliferation of NIH3T3 mouse embryonic fibroblast cell line and MDA-MB-231 human breast carcinoma cell line was assessed by MTT [3-(4,5-Dimethylthiazol-2yl)-2,5-diphenyltetrazolium bromide] assay. Briefly, the cells $\left(2 \times 10^{4}\right.$ for NIH3T3 and $1 \times 10^{5}$ for MDA-MB-231) grown in 96-well plates were treated with varying concentrations of nanoparticles $(0-1000 \mu \mathrm{g} /$ $\mathrm{ml})$ for $24 \mathrm{hr}$ at $37^{\circ} \mathrm{C}$. The cells were further incubated with MTT $(0.5$ $\mathrm{mg} / \mathrm{ml}$ ) at $37^{\circ} \mathrm{C}$ for $3 \mathrm{hr}$, followed by addition of $200 \mu \mathrm{l}$ of isopropanol. The color intensity was measured at $570 \mathrm{~nm}$ using an Enzyme Linked Immunosorbent Assay (ELISA) reader. The experiments were performed in triplicates. The cell viability was plotted as percent of control [27].

\section{Radiolabelling and biodistribution studies}

Radiolabelling of gold nanoparticles with Tc-99m: Tc99m-gold nanoparticles were prepared by dissolving $10 \mathrm{mg}$ of gold nanoparticles in $1 \mathrm{ml}$ of distilled water, followed by the addition of $100 \mu \mathrm{g}$ of $\mathrm{SnCl}_{2} \cdot 2 \mathrm{H}_{2} \mathrm{O}$ and the $\mathrm{pH}$ was adjusted to 6.5 . Approximately Tc-99m $(2 \mathrm{mCi})$ was added to the content, mixed and incubated for $10-15 \mathrm{~min}$. The percent radiolabel was determined by using Instant Thin Layer Chromatography (ITLC) method [28].

Radiochemical Purity (RCP): The radiochemical purity of Tc$99 \mathrm{~m}$ with gold nanoparticle was estimated by Instant Thin Layer Chromatography (ITLC), using silica gel coated fibre sheets. ITLC was performed using $100 \%$ acetone and $0.9 \%$ saline as the mobile phase. A measured amount of 2-3 $\mu \mathrm{l}$ of the radiolabelled complex was applied at a point $1 \mathrm{~cm}$ from one end of an ITLC-SG strip, and allowed to run for approximately $10 \mathrm{~cm}$. Amount of reduced/hydrolyzed Tc$99 \mathrm{~m}$ was determined using pyridine: acetic acid: water $(3: 5: 1.5 \mathrm{v} / \mathrm{v})$ as mobile phase and ITLC as the stationary phase, and the radioactivity distribution over the strip was determined with a well counter (ECIL). Radiochemical Purity (RCP) was calculated as the fraction of 
Citation: Syed A, Raja R,Kundu GC, Gambhir S, Ahmad A, et al. (2013) Extracellular Biosynthesis of Monodispersed Gold Nanoparticles, their Characterization, Cytotoxicity Assay, Biodistribution and Conjugation with the Anticancer Drug Doxorubicin. J Nanomed Nanotechol 4: 156. doi:10.4172/2157-7439.1000156

Page 3 of 6

radioactivity that remained at the origin and was designated as percent (\%) RCP.

Biodistribution of radiolabelled nanoparticles: Male Sprauge Dawley rat weighing 180-220 gm was selected for evaluating the localization of the labelled complex. Tc99m-gold nanoparticles of 14.8 $\mathrm{MBq}(400 \mathrm{uCi})$ were administered through the penile vein of rat. The biodistribution studies of labelled gold nanoparticles were evaluated after 45 min post injection.

Conjugation of anticancer drug doxorubicin with gold nanoparticles: Biosynthesized gold nanoparticles were conjugated with anticancer drug doxorubicin. As mentioned earlier, biosynthesized nanomaterials are capped by a protein layer secreted by the fungus in the reaction mixture, during the process of biosynthesis. Free amino as well as carboxylic groups are present in the capped protein layer. The free carboxyl group present on these proteins was targeted to couple with the free amino group present on the doxorubicin. Carboxyl group on the nanoparticles surface was estimated as described by Ansary et al. [29]. The gold nanoparticles were conjugated to doxorubicin, with the help of free carboxyl by using the activator 1-Ethyl-3(3-Dimethylaminopropyl)-Carbodiimide (EDC). The coupling reaction was carried out in $5 \mathrm{ml}$ reaction volume of $50 \mathrm{mM}$ MES/ HEPES buffer, containing $250 \mu \mathrm{g}$ of gold nanoparticles and $250 \mu \mathrm{g}$ of doxorubicin was added to $5 \mathrm{mM}$ of EDC. Conjugation was performed at $30^{\circ} \mathrm{C}$. After stirring for $12 \mathrm{~h}$ at room temperature, the reaction mixture was concentrated under high vacuum and further purification of the doxorubicin-gold conjugate was done by HPLC (Waters), using $\mathrm{C}_{18}$ symmetry reverse phase column and gradient elution was carried out using Acetonitrile:Water (5\%:95\%), at a flow rate of $0.5 \mathrm{ml} / \mathrm{min}$. A dual wavelength recorder set at $253 \mathrm{~nm}$ and $530 \mathrm{~nm}$ was used to detect the doxorubicin and gold nanoparticles, respectively, from the column. Fluorescence measurements were carried out using a Perkin Elmer LS50B spectrofluorimeter.

\section{Results and Discussion}

Owing to the popularity gained by gold nanoparticles in the past due to their biocompatible nature, we directed our efforts in order to fabricate monodispersed, uniform gold nanoparticles, which could carry appreciable amounts of uniform quantities of drugs, and also pass easily through the kidneys thus, preventing any sort of toxicity or discomfort to the body. Using a thermophilic fungus Humicola spp., we have successfully synthesized and completely characterized monodispersed gold nanoparticles of 18-24 nm size, which are nonagglomerating due to natural capping by proteins secreted by the fungus are spherical in size, with remarkable shelf-life and high stability. Biocompatibility and cytotoxicity (MTT) assays show that our gold nanoparticles are not toxic to both normal (NIH3T3 mouse embryonic fibroblast) and cancer (MDA-MB-231 human breast carcinoma) cell lines, upto concentrations of $50 \mu \mathrm{g} / \mathrm{ml}$ and thus, can fearlessly be used for conjugation with drug in targeted drug delivery systems.

These gold nanoparticles were radiolabeled with Technitium$99 \mathrm{~m}$ to check their biodistribution, and it was found that major amounts reach the liver of the organism (rat). Keeping this in mind, we conjugated these gold nanoparticles with the anticancer drug Doxorubicin, which is widely used for the treatment of liver (hepatic) cancer. The asialoglycoprotein receptors are overexpressed on hepatic cancer tissues. The nano-drug conjugates until now require pullulan, which is a target molecule specific to the asialoglycoprotein receptors to help in binding to the liver tissues, after which the nanoparticles can lead to the endocytosis of drug into cancerous cells. Free drug would otherwise have been effluxed by the P-glycoproteins persistent in the cancer cells.

On the other hand, the nanoparticles which we have fabricated have a natural protein coat secreted by the fungus. Thus, these may directly bind to various multi-receptors overexpressed on cancer cells, terminating the requirement of any targeting agents like pullulan, etc. As our nanoparticles may bind to multiple receptors, they can be used in targeted drug delivery for a wide variety of cancers.

\section{Isolation of Humicola spp. from self heating compost}

A total of 10 (AAH-SHC-1 to AAH-SHC-10) cultures were isolated from self heating compost collected from Pune (Maharashtra, India). These cultures were brought to pure form, and were maintained on alkaline MGYP agar slants. Out of 10 cultures screened for gold nanoparticles production, only AAH-SHC-1 was found to produce extracellular monodispersed gold nanoparticles.

The fungus Humicola spp. grown on alkaline MGYP medium produces fast growing colonies. Colonies which initially appear offwhite and felt-like, turns grey with time due to commencement of sporulation of the surface, as seen on the upper side of petriplate (Figure 1a). Subsequently, the reverse side of colony turns brown and the agar substratum stains a deep brown or wine color (Figure 1b). The vegetative mycelium is hyaline, septate, thin walled, highly branched, and is differentiated into conidia on short lateral branches, functioning as undistinguished conidiophores. Conidia are attached at bulging conidiogenous cells. Conidia produced were single, apically positioned, globose or subglobose, brown and single celled. Conidia are attached terminally on the conidiogenous cells (Figure 1c-1f). Based on the above cultural and morphological features, the isolated strain has been identified as Humicola spp. (Thermomyces lanuginosus) [26]. To confirm these findings, molecular approaches were used to amplify ITS region of ribosomal DNA of the fungus. The ITS sequence analysis and homology alignment of isolate AAH-SHC-1, using BLAST and Clustal-W programme, respectively, revealed similarity with genus Humicola spp. (Thermomyces lanuginosus) (Genebank accession number JN600618). The phylogenetic studies also indicate that the closest relative of the fungus is Thermomyces lanuginosus (Humicola spp.)
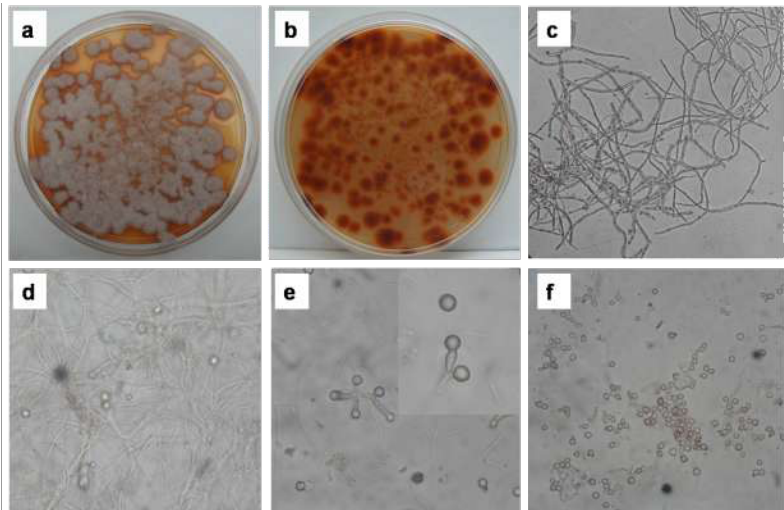

Figure 1: Morphological features of the fungus Humicola spp. The funga strain was grown on alkaline MGYP agar plate for microscopic observations. Fungal growth: front a) and back b) side of alkaline MGYP agar plate, $c$ and d) Mycelia, e) Attachment of the conidia on conidiophore, f) Conidia. 
Citation: Syed A, Raja R,Kundu GC, Gambhir S, Ahmad A, et al. (2013) Extracellular Biosynthesis of Monodispersed Gold Nanoparticles, their Characterization, Cytotoxicity Assay, Biodistribution and Conjugation with the Anticancer Drug Doxorubicin. J Nanomed Nanotechol 4: 156. doi:10.4172/2157-7439.1000156

Page 4 of 6
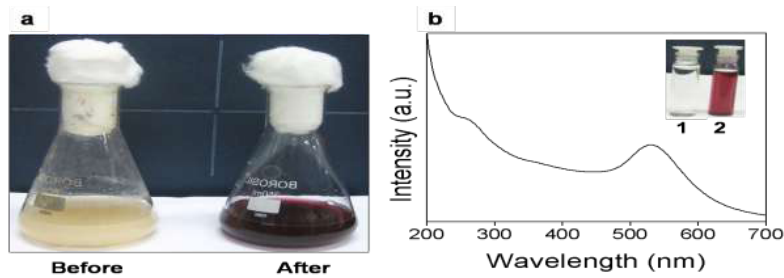

Figure 2: a) Conical flasks with fungus Humicola spp. before (flask on the left side) and after (flask on the right side) exposure to $\mathrm{HAuCl}_{4}$ ions for $96 \mathrm{hr}$ b). UV-vis spectra recorded for the gold nanoparticles, inset shows the bottle containing filtrate of the control flask (1) and filtrate of treated flask with the fungus containing gold nanoparticles (2).
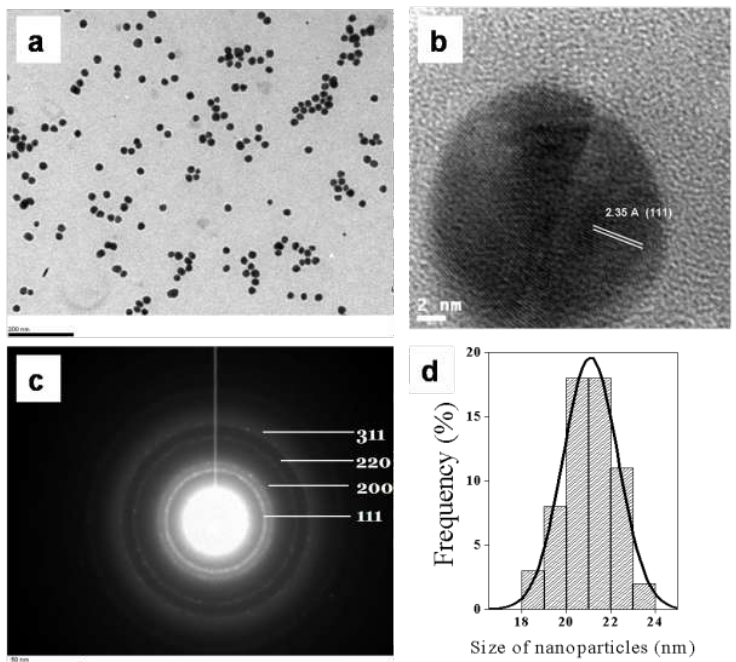

Figure 3: a) TEM micrograph recorded for gold nanoparticles, b) HRTEM micrograph, c) Selected area electron diffraction (SAED) pattern recorded from extracellular gold nanoparticles shown in Figure 3a, d) Particle size distribution histogram.

\section{Biosynthesis and characterization of gold nanoparticles by Humicola spp.}

The fungus Humicola spp., when incubated with aqueous solution of $1 \mathrm{mM} \mathrm{HAuCl}_{4}$, at temperature $50^{\circ} \mathrm{C}$ and $\mathrm{pH} 9$ for $96 \mathrm{hr}$ under shaking condition on a rotary shaker $(200 \mathrm{rpm})$, resulted in the production of extracellular, monodispersed and water dispersible gold nanoparticles. Figure 2a shows two conical flasks with the fungal biomass, before (left side) and after (right side) exposure to $1 \mathrm{mM} \mathrm{HAuCl}_{4}$ solution at $50^{\circ} \mathrm{C}$ for $96 \mathrm{hr}$. The change in color from pale yellow to vivid ruby red after incubation with fungus could clearly be seen in Figure 2a, which demonstrates the formation of Au nanoparticles by the fungal biomass. This change of color appears due to the surface plasmon resonance of $\mathrm{Au}$ nanoparticles. Biosynthesis of gold nanoparticles was monitored by UV-Vis spectroscopy, and it was observed that the surface plasmon band which occurs at $\sim 530 \mathrm{~nm}$ corresponds to the surface plasmon resonance of gold nanoparticles [30]. The fact that the surface plasmon band in the gold nanoparticle solution remains close to $530 \mathrm{~nm}$ throughout the reaction period indicates that the particles are dispersed in the aqueous solution, with no evidence for aggregation. These gold nanoparticles were separated from the fungal biomass by filtration after completion of the reaction; this demonstrates the extracellular nature of the produced nanoparticles (Figure $2 \mathrm{~b}$ ). An absorption band centered at $270 \mathrm{~nm}$, which can be attributed to the presence of protein secreted by the fungus in the reaction mixture, can be clearly seen in the UV-Vis spectrum of the biosynthesized gold nanoparticles. These nanoparticles are thus stabilized in solution by the capping agent secreted by the fungus, which is likely to be a protein or set of proteins, which prevent aggregation and make the nanoparticles stable and water dispersible.

Morphology and size distribution profile of the biosynthesized nanoparticles was obtained by TEM analysis. These gold nanoparticles are monodispersed (Figure $3 \mathrm{a}$ and $3 \mathrm{~b}$ ), sized in between 18-24 nm, with average size approximately $20 \mathrm{~nm}$ (Figure $3 \mathrm{~d}$ ). These particles are very well dispersed in solution, which is due to the capping agent likely to be a protein. Figure 3c shows the Selected Area Electron Diffraction (SAED) pattern obtained from gold nanoparticles shown in figure 3a. The Scherrer ring pattern, characteristic of face centered cubic (fcc) gold is clearly observed, showing that the structures seen in TEM images are nanocrystalline in nature. The HRTEM micrograph showed that the inter planar distance is $2.35 \AA$, which exactly matches with the (111) plane of the gold nanoparticles.

XRD analysis in figure 4a showed the crystalline nature of nanoparticles. The presence of four prominent Bragg's reflection, corresponding to the (111), (200), (220) and (311) orientations, agree with those reported for gold nanoparticles [22], and interestingly the broadness of these reflection demonstrates that the formed particles are in the nanoscale dimension. XPS measurement revealed the chemical nature of the nanoparticles, as seen in figure $4 \mathrm{~b}$. The $\mathrm{Au} 4 \mathrm{f}$ spectrum could be resolved into two peaks ( $\mathrm{Au} 4 \mathrm{f}_{7 / 2}$ and $4 \mathrm{f}_{5 / 2}$ ) due to the spinorbit coupling, with binding energy of 84.2 and $87.6 \mathrm{eV}$, respectively. The core level Binding Energy (BE) was aligned with $285 \mathrm{eV}$ (binding energy of carbon). These binding energies are characteristic of metallic gold and agree with those reported for gold nanoparticles.
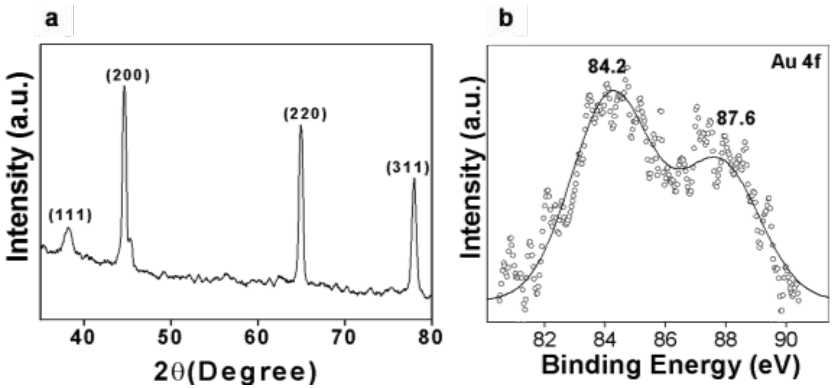

Figure 4: a) XRD pattern recorded for gold nanoparticles, b) X-ray photoelectron spectrum of gold nanoparticles.
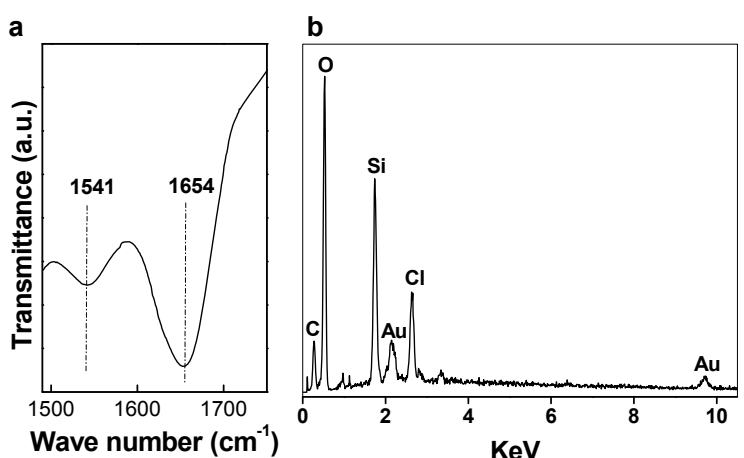

Figure 5: a) FTIR spectrum of gold nanoparticles, b) EDAX analysis of gold nanoparticles. 
Citation: Syed A, Raja R,Kundu GC, Gambhir S, Ahmad A, et al. (2013) Extracellular Biosynthesis of Monodispersed Gold Nanoparticles, their Characterization, Cytotoxicity Assay, Biodistribution and Conjugation with the Anticancer Drug Doxorubicin. J Nanomed Nanotechol 4: 156. doi:10.4172/2157-7439.1000156

The fungus secretes biomolecules/proteins in reaction mixture, thus, formation and stabilization of nanoparticles occurs. To support these findings, FTIR analysis was performed and the results in figure $5 \mathrm{a}$ suggest two bands appearing at 1654 and $1541 \mathrm{~cm}^{-1}$, assigned to amide I and II of proteins respectively [21]. Moreover, there is a possibility of stabilization of the gold nanoparticles by surface binding protein, either by free amino group or by cysteine residues present in the protein. EDAX spectrum in figure $5 \mathrm{~b}$ represents signals from $\mathrm{Au}(2.15$ and 9.70 $\mathrm{keV}$ ), together with $\mathrm{C}, \mathrm{O}$ and $\mathrm{Si}$. The secreted biomolecules contribute $\mathrm{C}$ and $\mathrm{O}$ signals in spectrum, whereas $\mathrm{Si}$ signal likely appears from the glass substrate used for EDAX analysis.

\section{Cell viability assay of gold nanoparticles}

The effect of gold nanoparticles on the cell viability of NIH3T3 mouse embryonic fibroblast cell line and MDA-MB-231 human breast carcinoma cell line was assessed by MTT assay. The cells were treated with varying concentrations of gold nanoparticles $(50 \mu \mathrm{g} / \mathrm{ml}, 250 \mu \mathrm{g} /$ $\mathrm{ml}, 5000 \mu \mathrm{g} / \mathrm{ml}$ and $1000 \mu \mathrm{g} / \mathrm{ml}$ ) for $24 \mathrm{hr}$. There is no significant difference on cell viability at concentration of $50 \mu \mathrm{g} / \mathrm{ml}$. The cell viability was reduced in a dose-dependent manner, in both the cell lines and the significant cytotoxicity of the nanoparticle was observed from concentrations of $250 \mu \mathrm{g} / \mathrm{ml}$ and above, for both the cell lines. The cell viability was reduced by $52 \%$ in case of NIH3T3 and $71.17 \%$ for MDAMB-231 cell line at $1000 \mu \mathrm{g} / \mathrm{ml}$ concentration (Figure 6a).

\section{Radiolabelling and biodistribution studies}

Complex formation study: On the basis of chromatographic analysis, the radiolabeling efficiency was found to be consistently more than $99 \%$. The optimal labeling efficiency was obtained with $100 \mu \mathrm{g}$ of stannous chloride (the concentration of $\mathrm{SnCl}_{2} \cdot 2 \mathrm{H}_{2} \mathrm{O}$ was varied from $50-100 \mu \mathrm{g})$, and at $\mathrm{pH} 6.5$.

Biodistribution and gamma scintigraphic imaging of Tc99mgold nanoparticles: Localization and biodistribution study of Tc99mgold nanoparticle in normal healthy rat over time was determined by gamma camera imaging, as shown in figure $6 \mathrm{~b}$. The study clearly indicates the biodistribution of the complex (Tc99m-gold nanoparticle) in above mentioned rat. These gold nanoparticles reach out to the liver, heart and kidneys, and pass out through the urine within 45 minutes.
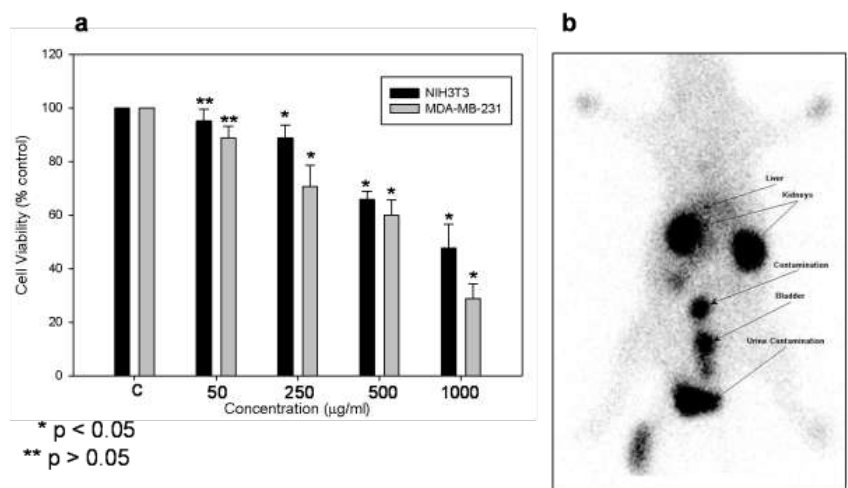

Figure 6: a) Cell viability assay of gold nanoparticles against NIH3T3 mouse embryonic fibroblast cell line and MDA-MB-231 human breast carcinoma cell line. The data represented in the form of a bar graph and plotted using means + S.E. of triplicate determinations. The values were analyzed by Student's $t$-test $(p<0.005)$, statistical analysis, $P$ values for significantly different means, ${ }^{*} \mathrm{P}<0.05$ and ${ }^{* *} \mathrm{P}>0.05$ vs control, b) Gamma scintigraphic image showing biodistribution of biosynthesized gold nanoparticles in rat.
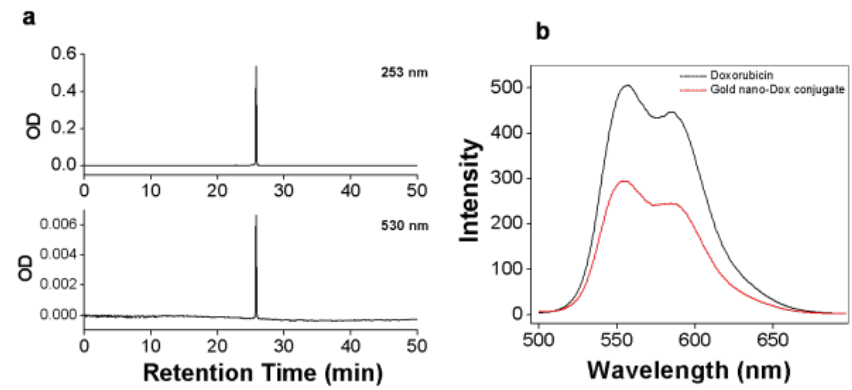

Figure 7: a) HPLC profile of the purified gold nanoparticles-doxorubicin conjugate at two dual wavelengths $(253 \mathrm{~nm}$ for doxorubicin and $530 \mathrm{~nm}$ to detect gold nanoparticles), b) Fluorescence emission spectrum of doxorubicin and gold nanoparticle-doxorubicin conjugate excited at $480 \mathrm{~nm}$.

The secreted protein in the reaction mixture provides dual function of formation and stabilization of nanoparticles. The free carboxyl group present on these proteins was targeted to couple with the free amino group present on doxorubicin. After successful conjugation of gold nanoparticles with doxorubicin, the conjugate was further purified by HPLC, at dual wavelength $253 \mathrm{~nm}$ and $530 \mathrm{~nm}$. The purified conjugate shows maximum absorbance at both wavelengths, with retention time of $25.8 \mathrm{~min}$ (Figure 7a). There are no significant changes in fluorescence spectrum for doxorubicin and gold nanoparticles-doxorubicin conjugate after excitation at $480 \mathrm{~nm}$ (Figure 7b). Decrease in the peak intensity of doxorubicin after conjugation with gold nanoparticles is due to slight quenching of doxorubicin by gold nanoparticles.

\section{Conclusion}

In conclusion, we have isolated and purified a thermophilic fungus Humicola spp., and identified it on the basis of cultural, morphological and molecular techniques. This fungus produces extracellular, monodispersed, protein capped, water dispersible and highly stable gold nanoparticles, when reacted with aqueous solution of $\mathrm{HAuCl}_{4}$ To the best of our knowledge, this green biosynthesis approach for the production of monodispersed, uniform gold nanoparticles of 18-24 $\mathrm{nm}$ size, employing Humicola spp. is the first report of its kind. Since these nanoparticles are capped by natural proteins, they may directly bind to multiple-receptors such as LHRH, EGFR and EpCAM, without the involvement of any targeting agents. Also, our nanoparticles may bind to integrins and VEGFs, and help in the development of a novel anti-angiogenesis strategy, for the treatment of a wide range of solid tumors. Hence, these nanoparticles which were until now considered only as a carrier in targeted drug delivery systems may now be used directly as a drug. These may fulfill the emerging need for cheaper drugs in abundant amounts, with no side effects to the patients and non-hazardous to the environment.

\section{Acknowledgments}

Syed A thanks the Council of Scientific and Industrial Research (CSIR) New Delhi for Senior Research Fellowship. Ahmad A thanks the Department of Biotechnology, Govt. of India (New Delhi) for the Tata Innovation Fellowship award and financial support through NWP0035 CSIR, New Delhi. The authors thank Center for Materials Characterization (CMC), Pune for assistance regarding TEM measurements.

\section{References}

1. Fonseca C, Simões S, Gaspar R (2002) Paclitaxel-loaded PLGA nanoparticles: preparation, physicochemical characterization and in vitro anti-tumoral activity. J Control Release 83: 273-286.

2. Koziara JM, Whisman TR, Tseng MT, Mumper RJ (2006) In-vivo efficacy of 
Citation: Syed A, Raja R,Kundu GC, Gambhir S, Ahmad A, et al. (2013) Extracellular Biosynthesis of Monodispersed Gold Nanoparticles, their Characterization, Cytotoxicity Assay, Biodistribution and Conjugation with the Anticancer Drug Doxorubicin. J Nanomed Nanotechol 4: 156. doi:10.4172/2157-7439.1000156

novel paclitaxel nanoparticles in paclitaxel-resistant human colorectal tumors. J Control Release 112: 312-319.

3. Bhadra D, Bhadra S, Jain S, Jain NK (2003) A PEGylated dendritic nanoparticulate carrier of fluorouracil. Int J Pharm 257: 111-124.

4. Panyam J, Labhasetwar V (2004) Sustained cytoplasmic delivery of drugs with intracellular receptors using biodegradable nanoparticles. Mol Pharm 1: 77-84.

5. Liu Y, Miyoshi H, Nakamura M (2007) Nanomedicine for drug delivery and imaging: a promising avenue for cancer therapy and diagnosis using targeted functional nanoparticles. Int J Cancer 120: 2527-2537.

6. Ould-Ouali L, Noppe M, Langlois X, Willems B, Te Riele P, et al. (2005) Selfassembling PEG-p(CL-Co-TMC) copolymers for oral delivery of poorly watersoluble drugs: a case study with risperidone. J Control Release 102: 657-668.

7. Kipp JE (2004) The role of solid nanoparticle technology in the parenteral delivery of poorly water-soluble drugs. Int J Pharm 284: 109-122.

8. Koziara JM, Whisman TR, Tseng MT, Mumper RJ (2006) In-vivo efficacy of novel paclitaxel nanoparticles in paclitaxel-resistant human colorectal tumors. J Control Release 112: 312-319.

9. Koziara JM, Lockman PR, Allen DD, Mumper RJ (2004) Paclitaxel nanoparticles for the potential treatment of brain tumors. J Control Release 99: 259-269.

10. Bhattacharyya S, Khan JA, Curran GL, Robertson JD, Bhattacharya R, et al. (2011) Efficient delivery of gold nanoparticles by dual receptor targeting. Adv Mater 23: 5034-5038.

11. Guhagarkar SA, Majee SB, Samad A, Devarajan PV (2011) Evaluation of pullulan-functionalized doxorubicin nanoparticles for asialoglycoprotein receptor-mediated uptake in Hep G2 cell line. Cancer Nanotechnol 2: 49-55.

12. Hussain S, Plückthun A, Allen TM, Zangemeister-Wittke U (2007) Antitumor activity of an epithelial cell adhesion molecule targeted nanovesicular drug delivery system. Mol Cancer Ther 6: 3019-3027.

13. Chittaranjan P, Bhattacharya R, Mukhopadhyay D, Mukherjee P (2008) Application of gold nanoparticles for targeted therapy in cancer. J Biomed Nanotechnol 4: 99-132.

14. Guhagarkar SA, Gaikwad RV, Samad A, Malshe VC, Devarajan PV (2010) Polyethylene sebacate-doxorubicin nanoparticles for hepatic targeting. Int J Pharm 401: 113-122

15. Bhattacharyya S, Kudgus RA, Bhattacharya R, Mukherjee P (2011) Inorganic nanoparticles in cancer therapy. Pharm Res 28: 237-259.

16. Ahmad A, Jagadale T, Dhas V, Khan S, Patil S, et al. (2007) Fungus-based synthesis of chemically difficult-to-synthesize multifunctional nanoparticles of CuAlO. Adv Mater 19: 3295-3299.
17. Shankar SS, Rai A, Ankamwar B, Singh A, Ahmad A, et al. (2004) Biological synthesis of triangular gold nanoprisms. Nat Mater 3: 482-488.

18. Bansal V, Ahmad A, Sastry M (2006) Fungus-mediated biotransformation of amorphous silica in rice husk to nanocrystalline silica. J Am Chem Soc 128 : 14059-14066.

19. Bansal V, Poddar P, Ahmad A, Sastry M (2006) Room-temperature biosynthesis of ferroelectric barium titanate nanoparticles. J Am Chem Soc 128: 1195811963

20. Ahmad A, Mukherjee P, Mandal D, Senapati S, Khan Ml, et al. (2002) Enzyme mediated extracellular synthesis of CdS nanoparticles by the Fungus, Fusarium oxysporum. J Am Chem Soc 124:12108-12109.

21. Ahmad A, Satyajyoti S, Khan MI, Kumar R, Sastry M (2003) Extracellular biosynthesis of monodisperse gold nanoparticles by a novel extremophilic actinomycete, Thermomonospora sp. Langmuir 19: 3550-3553.

22. Ahmad A, Senapati S, Khan MI, Kumar R, Ramani R, et al. (2003) Intracellula synthesis of gold nanoparticles by a novel alkalotolerent actinomycete Rhodococcus species. Nanotechnology 14: 824-828.

23. Ogale SB, Ahmad A, Pasricha R, Dhas VV, Syed A (2006) Physical manipulation of biological and chemical syntheses for nanoparticle shape and size control. Appl Phys Lett 89: 263105.

24. Shankar SS, Ahmad A, Pasricha R, Sastry M (2003) Bioreduction of chloroaurate ions by geranium leaves and its endophytic fungus yields gold nanoparticles of different shapes. J Mater Chem 13: 1822-1826.

25. Shukla R, Bansal V, Chaudhary M, Basu A, Bhonde RR, et al. (2005) Biocompatibility of gold nanoparticles and their endocytotic fate inside the cellular compartment: a microscopic overview. Langmuir 21: 10644-10654.

26. Syed AS (2011) Biological synthesis of inorganic nanoparticles and nanobioconjugates. Ph.D Thesis, 46-61.

27. Philip S, Kundu GC (2003) Osteopontin induces nuclear factor kappa B-mediated promatrix metalloproteinase-2 activation through I kappa B alpha /IKK signaling pathways, and curcumin (diferulolylmethane) down-regulates these pathways. J Biol Chem 278: 14487-14497.

28. Devarajan PV, Jindal AB, Patil RR, Mulla F, Gaikwad RV, et al. (2010) Particle shape: A new design parameter for passive targeting in splenotropic drug delivery. J Pharm Sci 99: 2576-2581.

29. Ansary AA, Kumar SA, Krishnasastry MV, Abyaneh MK, Kulkarni SK, et al (2007) CdS Quantum dots: Enzyme mediated in vitro synthesis, characterization and conjugation with plant lectins. J Biomed Nanotechnol 3: 406-413.

30. Mulvaney P (1996) Surface plasmon spectroscopy of nanosized metal particles. Langmuir 12: 788-800. 